\title{
Understanding the multi-scale structure and digestion rate of water chestnut starch
}

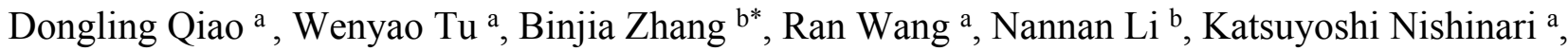
Saffa Riffat ${ }^{c}$, Fatang Jiang a,c*

${ }^{a}$ Glyn O. Phillips Hydrocolloid Research Centre at HBUT, School of Food and Biological Engineering, Hubei University of Technology, Wuhan 430068, China

${ }^{b}$ College of Food Science and Technology, Key Laboratory of Environment Correlative Dietology (Ministry of Education), Huazhong Agricultural University, Wuhan 430070, China

${ }^{c}$ Faculty of Engineering, University of Nottingham, Nottingham NG7 2RD, United Kingdom
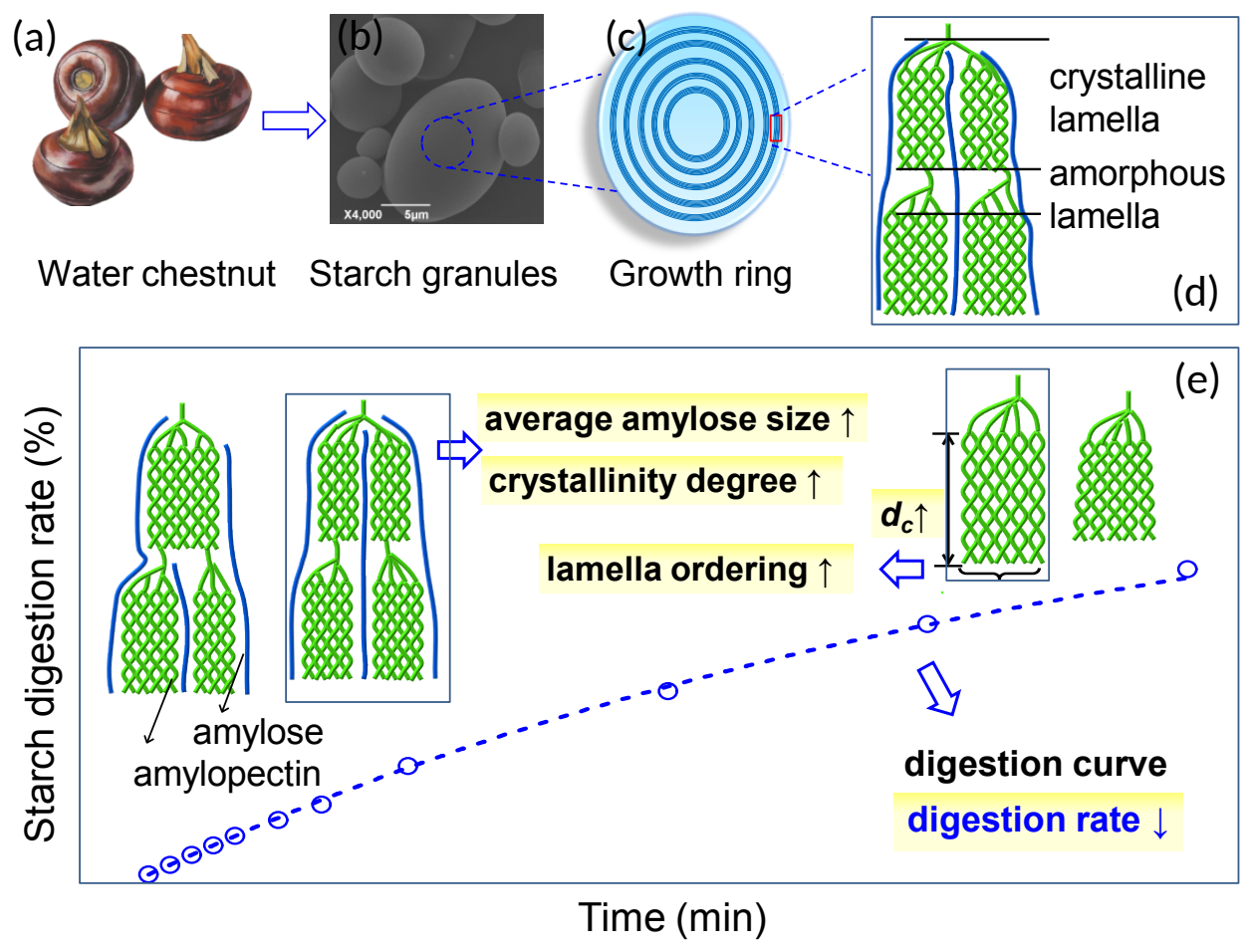

\footnotetext{
* Corresponding author. Email addresses: zhangbj@mail.hzau.edu.cn (B. Zhang); jiangft@mail.hbut.edu.cn (F. Jiang)
} 


\section{Understanding the multi-scale structure and digestion rate of water}

\section{2 chestnut starch}

4 Dongling Qiao ${ }^{\text {a }}$, Wenyao Tu ${ }^{\text {a }}$, Binjia Zhang ${ }^{\text {b* }}$, Ran Wang ${ }^{\text {a }}$, Nannan Li ${ }^{\text {b }}$, Katsuyoshi Nishinari ${ }^{\text {a }}$,

$5 \quad$ Saffa Riffat ${ }^{c}$, Fatang Jiang a,c*

6

$7 \quad{ }^{a}$ Glyn O. Phillips Hydrocolloid Research Centre at HBUT, School of Food and Biological

8 Engineering, Hubei University of Technology, Wuhan 430068, China

$9{ }^{b}$ Group for Grain and Oil Processing, College of Food Science and Technology, Key Laboratory of

10 Environment Correlative Dietology (Ministry of Education), Huazhong Agricultural University,

11 Wuhan 430070, China

$12{ }^{c}$ Faculty of Engineering, University of Nottingham, Nottingham NG7 2RD, United Kingdom

* Corresponding author. Email addresses: zhangbj@mail.hzau.edu.cn (B. Zhang); jiangft@mail.hbut.edu.cn (F. Jiang) 
17 Abstract: Using combined techniques and two comparisons (maize and cassava starches), this work concerns the multi-scale structure and digestion rate of water chestnut tuber starch. Among the

19 starches, the water chestnut starch showed altered hierarchical structural features and a relatively low

20 digestion rate. The underlying mechanism on the reduced digestion rate of water chestnut starch was

21 discussed from a hierarchical structural view. Specifically, compared with maize starch, the water

22 chestnut starch contained no pores on the granule surface, with the thickened crystalline lamellae, the

23 increased lamella ordering, and the elevated content of crystallites. Such structural features probably

24 increased the bulk density of molecule assembly in starch and thus could hinder the diffusion of

25 enzyme molecules in starch matrixes. Consequently, the absorption of enzyme to the starch glucan

26 chains could be retarded, resulting in a reduced enzyme hydrolysis rate of starch chains. The

27 relatively large amylose molecules of water chestnut starch also tended to reduce the starch digestion

28 rate, associated with the enhanced molecule interactions such as that between starch chains. In

29 addition, the further reduction in the digestion rate of cassava starch could be also ascribed to the

30 variations in the multi-scale structural features.

31 Keywords: water chestnut starch; multi-scale structure; digestion rate; structure-digestibility

32 relationship 


\section{Introduction}

Water chestnut (Eleocharis dulcis Burm. f., Cyperaceae) is a floating-leaved aquatic plant

grown in ponds for its round corms or tubers. The water chestnut tuber shows high nutritional value, as the tuber contains numerous bioactive components such as lectin, cysteine, proteinase inhibitor, quercetin, vitamins, fibers, essential fatty acids and minerals (Ansari, Ali, \& Hasnain, 2017). Haider, 2017). Starch is the major component of water chestnut tuber and is crucial in determining the quality of water chestnut products. For instance, the digestion of starch releases glucose that is

Besides, the water chestnut tuber has been used as versatile ingredients for foods or been consumed directly with special crunchy taste (Hummel \& Kiviat, 2004; Lutfi, Nawab, Alam, Hasnain, \& related to the metabolic diseases such as Type II diabetes (Ludwig, 2002; Morris \& Zemel, 1999), and thus can affect the health benefits of related foods.

Actually, there are two major biopolymers in starch, including relatively-linear amylose and hyper-branched amylopectin (Zobel, 1988). The molecular chains of the two biopolymers can assemble in the starch granule on multiple scales to construct a multi-scale structural system, including the whole granule, the growth rings, the lamellae, the crystallites, and the helices (Donald, et al., 1997; French, 1972; Tester, Karkalas, \& Qi, 2004; Zobel, 1988). The hierarchical (multi-scale) structural features can affect the physicochemical properties of starch including the digestibility. It is shown previously that the multi-scale structure containing tightly packed starch chains is less susceptible to the diffusion and hydrolysis of enzymes, which makes the digestion rate of native starch several times lower than that of fully cooked starch (Bertoft \& Manelius, 1992; Noda, et al., 2008). Thus, to thoroughly understand the starch properties such as digestion behaviors, it is indispensable to disclose the multi-scale structural features of starch as well as their relationship with 
digestibility.

Previous reports on water chestnut tuber starch are mainly focused on its physicochemical characteristics (Hizukuri, et al., 1988; Lan, Zhihua, Yun, Bijun, \& Zhida, 2008; Murty, Choudhury, \& Bagchi, 1962; Singh, Bawa, Singh, \& Saxena, 2009; Singh, et al., 2011; Tulyathan, Boondee, \& Mahawanich, 2005). Investigations have been implemented to explore the impact of freeze-thawed treatment on the microstructure, crystallinity, thermal properties, texture and resistant starch content of water chestnut starch (Wang, Yin, Wu, Sun, \& Xie, 2008). Also, there are findings regarding the functional properties of water chestnut starch as affected by additives such as xanthan (Gul, Riar, Bala, \& Sibian, 2014; Lutfi, et al., 2017) and modifications such as succinylation (Ansari, et al., 2017). However, to date, there is limited understanding for the digestibility, especially the digestion rate, of water chestnut starch from a view of multi-scale structural features. This prevents us from comprehensively linking the multi-scale structure of water chestnut starch to its properties, which is necessary for the rational design of water chestnut products.

To this end, the starch, isolated from a water chestnut tuber cultivated in Guangxi province in China, was used as the material. The widely used cereal starch (maize starch) and tuber starch (cassava starch) were applied as comparisons. Combined techniques spanning multiple length scales were adopted to evaluate the hierarchical structure and digestion rate of water chestnut starch. Among the three starches, the water chestnut starch had varied hierarchical structural features and thus a relatively low digestion rate. Then, how the digestion rate of water chestnut starch differs from other starches was discussed especially from a multi-scale structural view. 


\section{Materials and methods}

\subsection{Materials}

A water chestnut cultivated in Guangxi province in China was used in this study for starch isolation. The isolation procedures are detailed in section 2.2. Regular maize starch and cassava starch were purchased from Huanglong Food Industry Co. Ltd (China) and New Land Grain and Oil Processing Co. Ltd (China), respectively. $\alpha$-Amylase from porcine pancreas (A-3176; activity 25 unit/mg), and amyloglucosidase from Aspergillus niger (10115; activity 65 unit/mg) were supplied by Sigma-Aldrich.

\subsection{Isolation of water chestnut starch}

Starch was isolated from water chestnut using a method (Stevenson, Jane, \& Inglett, 2007) with modifications. Peeled and cut tuberous roots $\left(\right.$ about $\left.1 \mathrm{~cm}^{3}\right)$ were immersed into excess $0.3 \%(\mathrm{w} / \mathrm{v})$ aqueous sodium metabisulphite solution, followed by blending with a commercial blender (Joyoung JYL-C022, Shandong, China) at $26 \pm 2{ }^{\circ} \mathrm{C}$. The obtained puree was filtered through a screen of 106 $\mu \mathrm{m}$ mesh and the filtrate was maintained at $4{ }^{\circ} \mathrm{C}$ for $12 \mathrm{~h}$ to allow starch granules depositing. Then the supernatant was discarded and the rest was centrifuged at $8000 \mathrm{rpm}$ for $30 \mathrm{~min}$. The recovered starch was washed for three times with $0.1 \mathrm{M} \mathrm{NaCl}$, three times with ultrapure water and two times with absolute ethanol. The resulted starch was dried in a convection oven at $35^{\circ} \mathrm{C}$ for $48 \mathrm{~h}$, and the dried starch was ground and filtered through a 100-mesh steel screen for further usages. A moisture analyzer (YLS16A, Techcomp Ltd., China) was used to measure the moisture contents for the starches. The moisture contents for water chestnut, regular maize and cassava starches were $12.14 \%$, $12.39 \%$ and $12.70 \%$, respectively. 


\subsection{Scanning electron microscopy (SEM)}

A scanning electron microscope (JEOL-Model 6390, Japan) was used to observe the

morphology of granules of water chestnuts, maize and cassava starches. The samples were

$1041000 \times$ and $4000 \times$ were used for the samples under $15.0 \mathrm{kV}$ voltage.

\subsection{Laser diffraction analysis}

The granule size distributions for the starches were measured by a laser-diffraction analyzer

(Mastersizer 2000, Malvern, UK). Each starch was added to the reservoir and fully dispersed in distilled water at $26 \pm 2{ }^{\circ} \mathrm{C}$ until an obscuration value above $10 \%$ was achieved. All the results are the averages of three replicates.

\subsection{Small angle $X$-ray scattering $(S A X S)$}

SAXS measurements were performed on a NanoSTAR system (Bruker, Germany) operated at

$11430 \mathrm{~W}$. The $\mathrm{Cu} \mathrm{K} \alpha$ radiation $(\lambda=0.1542 \mathrm{~nm})$ was used as the X-ray source. A VÅnTeC-2000 detector 115 (active area $140 \times 140 \mathrm{~mm}^{2}$ and pixel size $68 \times 68 \mu \mathrm{m}^{2}$ ) was used to collect the scattering data.

116 Before the SAXS tests, the starch slurries ( $\mathrm{ca} .40 \%$, w/v) were kept under $26 \pm 2{ }^{\circ} \mathrm{C}$ for $4 \mathrm{~h}$ to leave 117 starch granules fully absorbing water. Empty cell with water was used as the background. All data 118 were background subtracted and normalized. The data in the range of $c a .0 .008<q<0.200 \AA^{-1}$ were 119 used as the SAXS results. The scattering vector, $q\left(\mathrm{~nm}^{-1}\right)$, was defined as $q=4 \pi \sin \theta / \lambda$ ( $2 \theta$, the 120 scattering angle) (Suzuki, Chiba, \& Yano, 1997). 


$$
f(r)=\frac{\int_{0}^{\infty} I(q) q^{2} \cos (q r) d q}{\int_{0}^{\infty} I(q) q^{2} d q}
$$

127 In which, $r(\mathrm{~nm})$ is the distance in real space, and $d$ represents the second maximum of $f(r)$ (the repeat distance, i.e., the average thickness of semicrystalline lamellae). $d_{\mathrm{a}}$ can be acquired by the

129 solution of the linear region and the flat $f(\mathrm{r})$ minimum, and $d_{\mathrm{c}}$ is calculated by $d_{\mathrm{c}}=d-d_{\mathrm{a}}$.

\section{$2.6 X$-ray diffraction $(X R D)$}

The crystalline structure of the starches were inspected on an X-ray powder diffractometer (D8

133 Advance, Bruker, USA), operated at $40 \mathrm{kV}$ and $30 \mathrm{~mA}$. The XRD patterns were acquired for a $2 \theta$ range of $4-40^{\circ}$, with a step size of $0.02^{\circ}$ and a step rate of $0.5 \mathrm{~s}$ per step. The relative crystallinity $\left(X_{\mathrm{c}}\right.$,

\%) was calculated using the PeakFit software (Ver. 4.12) with Gaussian function (Lopez-Rubio,

136 Flanagan, Gilbert, \& Gidley, 2008) according to Eq. (2).

$$
X_{c}=\frac{\sum_{i=1}^{n} A_{c i}}{A_{t}}
$$


140 Where $A_{\mathrm{ci}}$ is the area under each crystalline peak with index $i$, and $A_{\mathrm{t}}$ is the total area of the 141 diffraction pattern.

\subsection{Size exclusion chromatography (SEC)}

The molecular structure of fully and debranched starches from water chestnut starch, maize starch and cassava starch were characterized with an Agilent 1100 Series SEC system (Agilent (Shimadzu RID-10A, Shimadzu Corporation, Kyoto, Japan), according to a reported method (Liu, Halley, \& Gilbert, 2010). The GRAM precolumn, GRAM 100 and GRAM 3000 columns (PPS $\mathrm{GmbH}$, Mainz, Germany) were used to separate the fully branched starch molecules, using and RID signal) were treated following a published method (Castro, Ward, Gilbert, \& Fitzgerald, 2005; Wang, et al., 2015) to obtain the SEC weigh chain-length distribution (CLD), denoted as $w\left(\log V_{\mathrm{h}}\right)$, of starch molecules as a function of $R_{\mathrm{h}}\left(V_{\mathrm{h}}\right.$, hydrodynamic volume; $R_{\mathrm{h}}$, the corresponding hydrodynamic radius).

To evaluate the SEC size distribution of debranched starch molecules, branched chains on starch molecules were exclusively and quantitatively cleaved by isoamylase, based on an earlier method (Liu, et al., 2010). After the treatment with isoamylase, the resulting debranched starch was 158 freeze-dried, and then dissolved in DMSO/LiBr solution for SEC analysis. The same Agilent 1100 SEC system, with GRAM precolumn, GRAM 100 and GRAM 1000 columns, were adopted to analyze the debranched starch molecules at a flow rate of $0.6 \mathrm{~mL} / \mathrm{min}$ at $80{ }^{\circ} \mathrm{C}$. SEC size distribution was plotted as both weight CLD $\left(w\left(\log V_{\mathrm{h}}\right)\right)$ and number CLD $\left(N_{\mathrm{de}}(\mathrm{DP})\right)(\mathrm{DP}$, degree of 
polymerization). The suffix $d e$ of $N$ represents debranched. Samples were analyzed in duplicated.

\subsection{Digestion behaviors}

According to a method (Qiao, et al., 2017) with modifications, in vitro starch digestion for each

sample was carried out in duplicated. $90.0 \mathrm{mg}$ of starch and $6.0 \mathrm{~mL}$ of deionized water were placed

in a centrifuge tube, followed by addition of $10.0 \mathrm{~mL}$ of $\mathrm{pH} 6.0$ sodium acetate buffer solution and

168 incubation at $37^{\circ} \mathrm{C}$ in water bath for $10 \mathrm{~min}$. Then, $5 \mathrm{~mL}$ of freshly prepared enzyme buffer solution

169 containing $42 \mathrm{unit} / \mathrm{mL} \alpha$-amylase and $42 \mathrm{unit} / \mathrm{mL}$ amyloglucosidase was pipetted into the tube

170 containing starch to be digested. Afterwards, $100 \mu \mathrm{L}$ of the digested solution was collected at each

time point and mixed with $900 \mu \mathrm{L}$ of ethanol to terminate the digestion. The glucose concentration of

172 the digestion solution was measured using a glucose oxidase/peroxidase reagent (GOPOD Reagent,

173 Megazyme) as reported previously (Zou, Sissons, Gidley, Gilbert, \& Warren, 2015). The glucose

174 solution $(1 \mathrm{mg} / \mathrm{mL})$ was used as the standard. The percentage of digested starch was calculated

175 according to Eq. (3).

$$
S D(\%)=A_{\text {sample }} \times \frac{100 \mu \mathrm{L} \times 1.0 \mathrm{mg} / \mathrm{mL}}{A_{\text {glucose }}} \times 10 \times 210 \times \frac{100 \%}{90 \mathrm{mg}} \times \frac{162}{180}
$$

Where, $S D$ is the percentage of starch digested; $A_{\text {sample }}$ and $A_{\text {glucose }}$ are the absorbance values for the starch digestion solution and glucose standard, respectively; the value of $10 \times 210$ is the computational multiple from $100 \mu \mathrm{L}$ aliquots to $21.0 \mathrm{~mL}$ reaction solution; $162 / 180$ is the transformation coefficient from glucose to starch in weight. 
combined with the non-linear curve fitting method was adopted to analyze the digestion rate of

plot can distinguish the number of specific digestions stages with specific digestion rates throughout the whole digestion period based on the changes in the slope of digestion pattern $(\ln (\mathrm{dC} t / \mathrm{d} t))$ against time $(t)$. Since LOS plot uses the numerical derivative of discrete rate data points which makes it inherent inaccurate regarding its resulting rate coefficient $\left(k_{\mathrm{LOS}}\right)$, non-linear curve fitting is employed to obtain the rate coefficient for the starch digestion $\left(k_{\text {fitting }}\right)$.

$$
\begin{aligned}
& C_{t}=C_{\infty}\left(1-e^{-k \times t}\right) \\
& \ln \frac{\mathrm{dC}_{t}}{\mathrm{dt}}=-k \times t+\ln \left(C_{\infty} \times k\right)
\end{aligned}
$$

In these equations, $C_{t}(\%)$ is the amount of starch digested at a given time $(\mathrm{t}(\mathrm{min})), C_{\infty}(\%)$ is the estimated percentage of starch digested at the end point of a digestion stage, and $k\left(\mathrm{~min}^{-1}\right)$ is the coefficient of starch digestion rate. The calculated digestion data $\left(\ln \left[\left(C_{i+2}-C_{i}\right) /\left(t_{i+2}-t_{i}\right)\right]\right)$ at each time point $\left(\left(t_{i+2}+t_{i}\right) / 2\right)$, except the last two points, was used to obtain the LOS pattern and the related 199 fit curve.

\subsection{Statistical analysis}




\section{Results and discussion}

\subsection{Granule features}

Fig. 1 includes the SEM micrographs of the water chestnut, maize and cassava starch granules.

210 The water chestnut starch showed oval, irregular, spherical and olive shapes, with a smooth exterior 211 surface, which agreed with earlier results (Ansari, et al., 2017; Singh, et al., 2009). The maize starch 212 exhibited a mixture of round shape and angular shape with four or five sides, and had some pores on 213 the granule surface (labeled by the green arrows); the cassava starch displayed spherically-, 214 irregularly- and bowl-shaped morphology with a relatively smooth surface.

The granule size distributions for the three starches are presented in Fig. 2, and the related parameters are listed in Table 1. The water chestnut starch displayed a bimodal distribution, as indicated by a larger peak I at $c a$. 3-40 $\mu \mathrm{m}$ and a smaller peak II at $c a .50-300 \mu \mathrm{m}$. But, the maize and cassava starches exhibited exclusively one peak in the range of mainly 4-50 $\mu \mathrm{m}$. The size parameters $\left(d_{(0.1)}, d_{(0.5)}, d_{(0.9)}\right.$ and $\left.\mathrm{D}[3,2]\right)$ revealed the smallest granule size for the water chestnut starch and the largest granule size for the maize starch, accompanied by an intermediate granule size

221 for the cassava starch. Besides, the span value $\left(=\left(d_{(0.9)}-d_{(0.1)}\right) / d_{(0.5)}\right)$ was applied to indicate the 222 width of granule size distribution (Fang, et al., 2008). The water chestnut starch and the cassava starches had the largest and the smallest span values respectively, and a value somewhere between them was seen for the maize starch. 


\subsection{Lamellar structure}

The alternating amorphous-crystalline (semicrystalline) lamellae on the nanoscale could be well explored by SAXS via a scattering peak at a $q$ value of $c a .0 .065 \AA^{-1}$ (Zhang, et al., 2017a; Zhang, et al., 2017b). The logarithmic SAXS patterns of water chestnut, maize and cassava starches are shown in Fig. 3, and the average thicknesses of semicrystalline $(d)$, crystalline $\left(d_{\mathrm{c}}\right)$ and amorphous $\left(d_{\mathrm{a}}\right)$ lamellae for the starches are recorded in Table 2. Among the starches, the water chestnut starch exhibited the largest $d$ and $d_{\mathrm{c}}$. Compared with the maize starch, the cassava starch possessed a smaller $d_{\mathrm{c}}$ and a larger $d_{\mathrm{a}}$, and thus a similar $d$.

Table 2 also collects the scattering peak area $\left(A_{\text {peak }}\right)$ that is positively correlated to the ordering degree of lamellar regions (Pikus, 2005). That is, a larger $A_{\text {peak }}$ indicates a more perfect organization of amorphous-crystalline lamellae. The results showed that the $A_{\text {peak }}$ value was in an order of maize starch $<$ cassava starch $<$ water chestnut starch. This indicates that the water chestnut and maize starches had the highest and the lowest lamellar ordering respectively, while the cassava starch display a lamellar ordering level close to (slightly lower than) that for the water chestnut starch.

\subsection{Crystalline structure}

XRD patterns of starch can be used to clearly distinguish its crystalline structure (A-, Band C-type) (Buléon, Colonna, Planchot, \& Ball, 1998; Perez \& Bertoft, 2010). Normally, the double-helices of the crystalline lamellae can be organized in monoclinic or hexagonal crystalline unit cells to form the A- and B-type allomorphs respectively (Gérard, Planchot, Colonna, \& Bertoft, 2000). Fig. 4 shows the XRD patterns of the three starches. All of the 
starches displayed a typical A-type polymorph with intense diffraction peaks at $c a .15^{\circ}$ and $23^{\circ}$, and an unresolved doublet at $c a .17^{\circ}$ and $18^{\circ}$. The crystallinity degrees $\left(X_{\mathrm{c}}\right)$ of the starches were calculated from the ratio of the total diffraction peak area to the total area of the diffraction patterns, and the results are listed in Table 2. Among the starches, the water chestnut starch possessed the highest crystallinity degree with a lowest one for the maize starch and an intermediate one for the cassava starch.

\subsection{Size distribution of whole starch molecules}

Typical SEC size distribution of fully branched molecules from the three starches are shown in

Fig. 5a, normalized to yield the same height of the highest peak for comparisons. The starches contained two populations of glucan polymers, i.e., amylose at smaller $R_{h}$ values (the hydrodynamic radius of the macromolecules) and amylopectin at larger $R_{h}$ values. Consistent with earlier work (Cave, Seabrook, Gidley, \& Gilbert, 2009), the amylose SEC size distribution was used to analyze the whole amylose molecule features (Fig. 5a), without taking amylopectin SEC size distribution into consideration due to the separation limit of SEC columns, unavoidable shear scission suffered, calibration limitation and low recovery. The amylose component is expressed as the average $R_{\mathrm{h}}$ of amylose ( $\bar{R}_{\mathrm{h} \text {, amylose }}$ ) as defined elsewhere (Vilaplana \& Gilbert, 2010), and the results for three

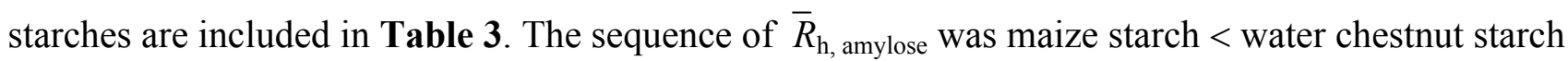
$<$ cassava starch, indicating that water chestnut starch had an intermediate amylose size that was smaller than that of cassava starch but larger than that of maize starch. 
are presented in Fig. 5b. All weight CLDs were normalized to yield the same global maximum to enable a relative comparison. The starches displayed usual features including two large peaks for amylopectin branches of DP $<100$ and multiple smaller bumps for amylose branches of DP $\geqslant 100$ (Li, Prakash, Nicholson, Fitzgerald, \& Gilbert, 2016).

The two amylopectin peaks corresponded to the branches confined to one single lamella range (Ap1; $0.5 \mathrm{~nm}<R_{\mathrm{h}}<2 \mathrm{~nm}$ or $5<\mathrm{DP}<30$ ) and those chain spanning more than a single lamella (Ap2; $2 \mathrm{~nm}<R_{\mathrm{h}}<4 \mathrm{~nm}$ or $\left.30<\mathrm{DP}<100\right)$. The height ratio $\left(h_{\mathrm{Ap} 2 / \mathrm{Ap} 1}\right)$ for the maximum of Ap2 peak to that of Ap1 peak represents the relative ratio of Ap2 chains to Ap1 chains. The $h_{\mathrm{Ap} 2 / \mathrm{Ap} 1}$ results in

Table 3 indicates that cassava starch had relatively more Ap2 chains than did water chestnut starch and maize starch. Also, the CLD of amylopectin chains, depicted as number distribution $\left(\ln N_{\mathrm{de}}(D P)\right)$ as a function of DP, is shown in Fig. 5c. Relative to other starches, the higher number CLD in the range of $30<\mathrm{DP}<100$ for cassava starch agreed well with its larger proportion of Ap2 chain.

For amylose component, apparent differences were observed in the weigh CLD among the starches (enlarged in Fig. 5d). The amylose weight CLD had three overlapping bumps, suggesting three corresponding groups. The first group (denoted by Am1) represents short amylose chains, covering DP 100-650, while the other two groups are intermediate and long amylose chains (denoted by Am2 and Am3), in the ranges of DP 650-2300 and DP 2300-30000, respectively. The areas under the respective peaks of $\mathrm{Am} 1\left(A_{\mathrm{Am} 1}\right), \operatorname{Am} 2\left(A_{\mathrm{Am} 2}\right)$ and $\mathrm{Am} 3\left(A_{\mathrm{Am} 3}\right)$ were used to indicate the relative amounts of corresponding amylose chains. Also, the amylose content was obtained from the weight CLD by calculating the ratio of the area under the curve of the whole amylose range (DP $>100)$ to the area under the curve of the whole starch distribution. The parameters $\left(A_{\mathrm{Am} 1}, A_{\mathrm{Am} 2}, A_{\mathrm{Am} 3}\right.$ and 
amylose content) for the starches are shown in Table 3. The $A_{\mathrm{Am} 1}$ of water chestnut starch was larger than that of cassava starch and similar to that of maize starch. The water chestnut starch had $A_{\mathrm{Am} 2}$ and $A_{\mathrm{Am} 3}$ values that were similar to those of cassava starch but smaller than those of maize starch.

For amylose content, the order of three starches was cassava starch $<$ water chestnut starch $\approx$ maize starch ranging from $20.01 \%$ to $25.90 \%$.

\subsection{Digestion behaviors}

The typical digestion curves and LOS plots, along with their fit curves, for water chestnut, maize and cassava starches are included in Fig. 6, and the related parameters of starch digestion are presented in Table 3. Clearly, only one linear range was shown in the LOS plot curve for three starches, identified by rate constant $k_{\text {LOS }}$, indicating that the digestion of those starches showed a monophasic digestion behavior and followed the first-order kinetics. Note that the digestion rate is a

304 function of enzyme concentration used in digestion experiment. Hence, the digestion process of 305 those starch is pseudo-first-order (Butterworth, et al., 2012). Due to the inherent inaccuracy for the obtained rate coefficient $\left(k_{\mathrm{LOS}}\right)$ from the LOS plot, this method was used only to distinguish the digestion steps and non-linear curve fitting was employed to acquire the rate coefficient for starch

digestion $\left(k_{\text {fitting }}\right)$. As shown in Table 3, the water chestnut starch had an intermediate digestion rate that was higher than that of cassava starch but lower than that of maize starch. After $12 \mathrm{~h}$ of cassava starch $(69.01 \%)$ and lower than that for maize starch $(82.11 \%)$. 

the starch digestion system. While $\alpha$-amylase cleaves $\alpha-1,4$ linkages at random location, amyloglucosidase hydrolyzes the terminal or next-to-terminal linkage starting at the non-reducing

317 end of glucose polymer. The digestion of starch granules is a heterogeneous reaction, involving the 318 diffusion of enzymes to the starch substrate followed by absorption and subsequent catalytic events 319 (Colonna, Leloup, \& Buléon, 1992; Zhang, Dhital, \& Gidley, 2013). The digestion rate is closely 320 related to the rate at which the enzyme diffuses into the substrate to form an enzyme-substrate complex. A series of factors, e.g., granule surface features, crystallinity and molecular structure, are found to affect the starch digestion rate (Blazek \& Copeland, 2010; Syahariza, Sar, Hasjim, Tizzotti, \& Gilbert, 2013), probably by altering the enzyme diffusion to starch substrate and then the interplay between the enzyme and the substrate.

Along with such theoretical basis as well as the multi-scale structural and digestion features discussed above, a schematic model is proposed for the structure-digestion relationship of water chestnut starch (Fig. 7). Compared to the maize starch, the water chestnut starch displayed no pores on the granule surface (discussed in Section 3.1), accompanied by the thickened crystalline lamellae, the increased ordering degree of lamellar regions, and the elevated proportion of crystallites (shown by results in Table 2). These structural features tended to increase bulk density of molecule assembly 331 in starch, and suppressed the diffusion of the enzyme molecules in the matrixes of starch substrate. In 332 this way, the absorption events of enzyme molecules to the starch glucan chains on the molecular scale were retarded, resulting in a reduced rate of the catalytic events (enzyme-induced glucan chains hydrolysis). Consistently, earlier findings confirm that the granule surface pores (with channels to granule interior) contribute to the migration of enzyme into the granule and thus accelerate the 
digestion (Shrestha, et al., 2012). Moreover, the fine molecular structure of both amylose and amylopectin could affect the digestion rate of starch. Previous findings showed that introducing branch points to the native tapioca starch by 1,4- $\alpha$-glucan branching enzyme (GBE) could enhance the steric hindrance effect to the enzymes and in turn decrease the rapidly digestible starch content

340 (Ren, et al., 2018). Moreover, it was found that the higher amylose content, the larger size of amylose chains and the lower amounts of shorter amylopectin chains may slow the digestion rate of starch (Xu, et al., 2017). The amylose molecules in water chestnut starch showed an increased size

343 (reflected by $\bar{R}_{\mathrm{h} \text {, amylose }}$ in Table 3), probably having a more linear or flexible structure, and thus 344 might effectively interact with amylose/amylopectin glucan chains and/or other compounds such as 


\section{Conclusions}

With maize starch and cassava starch as comparisons, this work provides an insight into the

hierarchical structure and the digestion rate of water chestnut starch. Relative to the regular maize starch, the water chestnut starch displayed following structural features: no pores on the granule surface, thicker crystalline lamellae, higher ordering of lamellae, elevated crystallites, and larger amylose molecules. Those structure features could hinder the enzyme molecule diffusion in the starch matrixes, retard the absorption of enzyme to the starch glucan chains and then slow the enzyme hydrolysis process for starch chains. Similarly, the further reduction in the digestion rate of

cassava starch could be ascribed to the relative higher $h_{\mathrm{Ap} 2 / \mathrm{Ap} 1}$. It is worth mentioning that the

digestion of starch granules with sophisticated structure is a very complicated process, and comprehensive explanation for this process cannot be obtained without very detailed studies of the mechanism by which the enzyme accesses and hydrolyzes starch chains. Here, this work tried to give a probable explanation on the relatively low digestion rate of water chestnut starch from a multiscale structural view. More efforts, especially involving how enzymes access and hydrolyze starch chains, should be made to better understand the digestion features of water chestnut starch.

\section{Acknowledgments}

The authors would like to acknowledge the National Natural Science Foundation of China 
Scientific Research Project from Hubei Province Department of Education (Q20181407), and the

European Commission for the H2020 Marie Skłodowska-Curie Actions Individual Fellowships-2017

Project (794680). The authors also would like to thank Dr. Cheng Li, Dr. Enpeng Li and Mr. Shiqing

Zhou from Prof. Robert Gilbert's lab at Yangzhou University for their assistance on SEC experiment and analysis. B. Zhang thank the Young Elite Scientists Sponsorship Program by China Association for Science and Technology.

\section{References}

Ansari, L., Ali, T. M., \& Hasnain, A. (2017). Effect of chemical modifications on morphological and functional characteristics of water-chestnut starches and their utilization as a fat-replacer in low-fat mayonnaise. Starch - Stärke, 69(1-2), 1600041-n/a.

Bertoft, E., \& Manelius, R. (1992). A method for the study of the enzymic hydrolysis of starch granules. Carbohydrate Research, 227, 269-283.

Blazek, J., \& Copeland, L. (2010). Amylolysis of wheat starches. II. Degradation patterns of native starch granules with varying functional properties. Journal of Cereal Science, 52(2), 295-302.

Buléon, A., Colonna, P., Planchot, V., \& Ball, S. (1998). Starch granules: structure and biosynthesis. International Journal of Biological Macromolecules, 23(2), 85-112.

Butterworth, P. J., Warren, F. J., Grassby, T., Patel, H., \& Ellis, P. R. (2012). Analysis of starch amylolysis using plots for first-order kinetics. Carbohydrate Polymers, 87(3), 2189-2197.

Castro, J. V., Ward, R. M., Gilbert, R. G., \& Fitzgerald, M. A. (2005). Measurement of the Molecular Weight Distribution of Debranched Starch. Biomacromolecules, 6(4), 2260-2270. 
Cave, R. A., Seabrook, S. A., Gidley, M. J., \& Gilbert, R. G. (2009). Characterization of Starch by Size-Exclusion Chromatography: The Limitations Imposed by Shear Scission. Biomacromolecules, 10(8), 2245-2253.

Colonna, P., Leloup, V., \& Buléon, A. (1992). Limiting factors of starch hydrolysis. European journal of clinical nutrition, 46 Suppl 2, S17-32.

Donald, A. M., Waigh, T. A., Jenkins, P. J., Gidley, M. J., Debet, M., \& Smith, A. (1997). Internal structure of starch granules revealed by scattering studies. In P. J. Frazier, A. M. Donald \& P. Richmond (Eds.), Starch: Structure and Functionality (pp. 172-179). Cambridge: The Royal Society of Chemistry.

Fang, Y.-y., Wang, L.-j., Li, D., Li, B.-Z., Bhandari, B., Chen, X. D., \& Mao, Z.-h. (2008). Preparation of crosslinked starch microspheres and their drug loading and releasing properties. Carbohydrate Polymers, 74(3), 379-384.

French, D. (1972). Fine Structure of Starch and its Relationship to the Organization of Starch Granules. Journal of the Japanese Society of Starch Science, 19(1), 8-25.

Gérard, C., Planchot, V., Colonna, P., \& Bertoft, E. (2000). Relationship between branching density and crystalline structure of A- and B-type maize mutant starches. Carbohydrate Research, $326(2), 130-144$.

Gul, K., Riar, C. S., Bala, A., \& Sibian, M. S. (2014). Effect of ionic gums and dry heating on physicochemical, morphological, thermal and pasting properties of water chestnut starch. LWT - Food Science and Technology, 59(1), 348-355.

Hizukuri, S., Takeda, Y., Shitaozono, T., Abe, J., Ohtakara, A., Takeda, C., \& Suzuki, A. (1988). Structure and Properties of Water Chestnut (Trapa natans L. var. bispinosa Makino) Starch. 
Hummel, M., \& Kiviat, E. (2004). Review of World literature on Water Chestnut with implications for management in North America. Journal of Aquatic Plant Management, 42, 17-27.

Lan, W., Zhihua, Y., Yun, Z., Bijun, X., \& Zhida, S. (2008). Morphological, Physicochemical and Textural Properties of Starch Separated from Chinese Water Chestnut. Starch - Stärke, 60(34), 181-191.

Li, H., Prakash, S., Nicholson, T. M., Fitzgerald, M. A., \& Gilbert, R. G. (2016). The importance of amylose and amylopectin fine structure for textural properties of cooked rice grains. Food Chemistry, 196, 702-711.

Liu, W.-C., Halley, P. J., \& Gilbert, R. G. (2010). Mechanism of Degradation of Starch, a Highly Branched Polymer, during Extrusion. Macromolecules, 43(6), 2855-2864.

Lopez-Rubio, A., Flanagan, B. M., Gilbert, E. P., \& Gidley, M. J. (2008). A novel approach for calculating starch crystallinity and its correlation with double helix content: A combined XRD and NMR study. Biopolymers, 89(9), 761-768.

Ludwig, D. S. (2002). The glycemic index: Physiological mechanisms relating to obesity, diabetes, and cardiovascular disease. JAMA, 287(18), 2414-2423.

Lutfi, Z., Nawab, A., Alam, F., Hasnain, A., \& Haider, S. Z. (2017). Influence of xanthan, guar, CMC and gum acacia on functional properties of water chestnut (Trapa bispinosa) starch. International Journal of Biological Macromolecules, 103, 220-225.

Morris, K. L., \& Zemel, M. B. (1999). Glycemic Index, Cardiovascular Disease, and Obesity. Nutrition Reviews, 57(9), 273-276.

Murty, V. L. N., Choudhury, D., \& Bagchi, P. (1962). Physicochemical studies of water chestnut 
starch (Trapa bispinosa Roxb). Canadian Journal of Chemistry, 40(12), 2260-2266.

Noda, T., Takigawa, S., Matsuura-Endo, C., Suzuki, T., Hashimoto, N., Kottearachchi, N. S., Yamauchi, H., \& Zaidul, I. S. M. (2008). Factors affecting the digestibility of raw and gelatinized potato starches. Food Chemistry, 110(2), 465-470.

Perez, S., \& Bertoft, E. (2010). The molecular structures of starch components and their contribution to the architecture of starch granules: A comprehensive review. Starch/Stärke, 62(8), 389420.

Pikus, S. (2005). Small-angle X-ray scattering (SAXS) studies of the structure of starch and starch products. Fibres and Textiles in Eastern Europe, 13(5), 82-86.

Qiao, D., Xie, F., Zhang, B., Zou, W., Zhao, S., Niu, M., Lv, R., Cheng, Q., Jiang, F., \& Zhu, J. (2017). A further understanding of the multi-scale supramolecular structure and digestion rate of waxy starch. Food Hydrocolloids, 65, 24-34.

Qiao, D., Yu, L., Liu, H., Zou, W., Xie, F., Simon, G., Petinakis, E., Shen, Z., \& Chen, L. (2016). Insights into the hierarchical structure and digestion rate of alkali-modulated starches with different amylose contents. Carbohydrate Polymers, 144, 271-281.

Ren, J., Li, C., Gu, Z., Cheng, L., Hong, Y., \& Li, Z. (2018). Digestion rate of tapioca starch was lowed through molecular rearrangement catalyzed by 1,4- $\alpha$-glucan branching enzyme. Food Hydrocolloids, 84, 117-124.

Shrestha, A. K., Blazek, J., Flanagan, B. M., Dhital, S., Larroque, O., Morell, M. K., Gilbert, E. P., \& Gidley, M. J. (2012). Molecular, mesoscopic and microscopic structure evolution during amylase digestion of maize starch granules. Carbohydrate Polymers, 90(1), 23-33.

Singh, G. D., Bawa, A. S., Singh, S., \& Saxena, D. C. (2009). Physicochemical, Pasting, Thermal 
and Morphological Characteristics of Indian Water Chestnut (Trapa natans) Starch. Starch Stärke, 61(1), 35-42.

Singh, G. D., Riar, C. S., Saini, C., Bawa, A. S., Sogi, D. S., \& Saxena, D. C. (2011). Indian water chestnut flour- method optimization for preparation, its physicochemical, morphological, pasting properties and its potential in cookies preparation. LWT - Food Science and Technology, 44(3), 665-672.

Stevenson, D. G., Jane, J.-1., \& Inglett, G. E. (2007). Characterisation of Jícama (Mexican Potato) (Pachyrhizus erosus L. Urban) Starch From Taproots Grown in USA and Mexico. Starch Stärke, 59(3-4), 132-140.

Suzuki, T., Chiba, A., \& Yano, T. (1997). Interpretation of small angle X-ray scattering from starch on the basis of fractals. Carbohydrate Polymers, 34(4), 357-363.

Syahariza, Z. A., Sar, S., Hasjim, J., Tizzotti, M. J., \& Gilbert, R. G. (2013). The importance of amylose and amylopectin fine structures for starch digestibility in cooked rice grains. Food Chemistry, 136(2), 742-749.

Tester, R. F., Karkalas, J., \& Qi, X. (2004). Starch-composition, fine structure and architecture. Journal of Cereal Science, 39(2), 151-165.

Tulyathan, V., Boondee, K., \& Mahawanich, T. (2005). Characteristics of starch from water chestnut (Trapa Bispinosa Roxb.). Journal of Food Biochemistry, 29(4), 337-348.

Vilaplana, F., \& Gilbert, R. G. (2010). Two-Dimensional Size/Branch Length Distributions of a Branched Polymer. Macromolecules, 43(17), 7321-7329.

Wang, K., Wambugu, P. W., Zhang, B., Wu, A. C., Henry, R. J., \& Gilbert, R. G. (2015). The biosynthesis, structure and gelatinization properties of starches from wild and cultivated 
African rice species (Oryza barthii and Oryza glaberrima). Carbohydrate Polymers, 129, 92100.

Wang, L., Yin, Z., Wu, J., Sun, Z., \& Xie, B. (2008). A study on freeze-thaw characteristics and microstructure of Chinese water chestnut starch gels. Journal of Food Engineering, 88(2), 186-192.

Xu, J., Kuang, Q., Wang, K., Zhou, S., Wang, S., Liu, X., \& Wang, S. (2017). Insights into molecular structure and digestion rate of oat starch. Food Chemistry, 220, 25-30.

Yu, W., Tao, K., \& Gilbert, R. G. (2018). Improved methodology for analyzing relations between starch digestion kinetics and molecular structure. Food Chemistry, 264, 284-292.

Zhang, B., Dhital, S., \& Gidley, M. J. (2013). Synergistic and Antagonistic Effects of $\alpha$-Amylase and Amyloglucosidase on Starch Digestion. Biomacromolecules, 14(6), 1945-1954.

Zhang, B., Xie, F., Shamshina, J. L., Rogers, R. D., McNally, T., Halley, P. J., Truss, R. W., Chen, L., \& Zhao, S. (2017a). Dissolution of Starch with Aqueous Ionic Liquid under Ambient Conditions. Acs Sustainable Chemistry \& Engineering, 5(5), 3737-3741.

Zhang, B., Xie, F., Wang, D. K., Zhao, S., Niu, M., Qiao, D., Xiong, S., Jiang, F., Zhu, J., \& Yu, L. (2017b). An improved approach for evaluating the semicrystalline lamellae of starch granules by synchrotron SAXS. Carbohydrate Polymers, 158, 29-36.

Zobel, H. F. (1988). Molecules to Granules: A Comprehensive Starch Review. Starch - Stärke, 40(2), 44-50.

Zou, W., Sissons, M., Gidley, M. J., Gilbert, R. G., \& Warren, F. J. (2015). Combined techniques for characterising pasta structure reveals how the gluten network slows enzymic digestion rate. Food Chemistry, 188, 559-568. 


\section{Figure Captions}

513 Fig. 1 SEM images of the starch granules from water chestnut, maize and cassava starch.

514 Fig. 2 Granule size distributions of water chestnut, maize and cassava starches.

515 Fig. 3 Logarithmic SAXS patterns of water chestnut, maize and cassava starches.

516 Fig. 4 XRD patterns of powders of water chestnut, maize and cassava starches.

517 Fig. 5 Weight size distribution of whole starch molecules (a), weight size distribution and chain-

518 length distribution of debranched starch molecules (b), number chain-length distribution of

519 debranched amylopectin molecules (c), and weight size distribution and chain-length distribution of

520 debranched amylose molecules (d) from water chestnut, maize and cassava samples.

521 Fig. 6 Typical digestion curves, LOS plots and nonlinear fitting curves for water chestnut, maize and

522 cassava starches. $\bigcirc$, experimental data; ${ }^{*}$, LOS plot data; - - - , linear fit curve for LOS plot

523 data; ----, fit curves based on non-linear curve fitting method.

524 Fig. 7 Schematic representation for the structure-digestion relationship for water chestnut starch. 

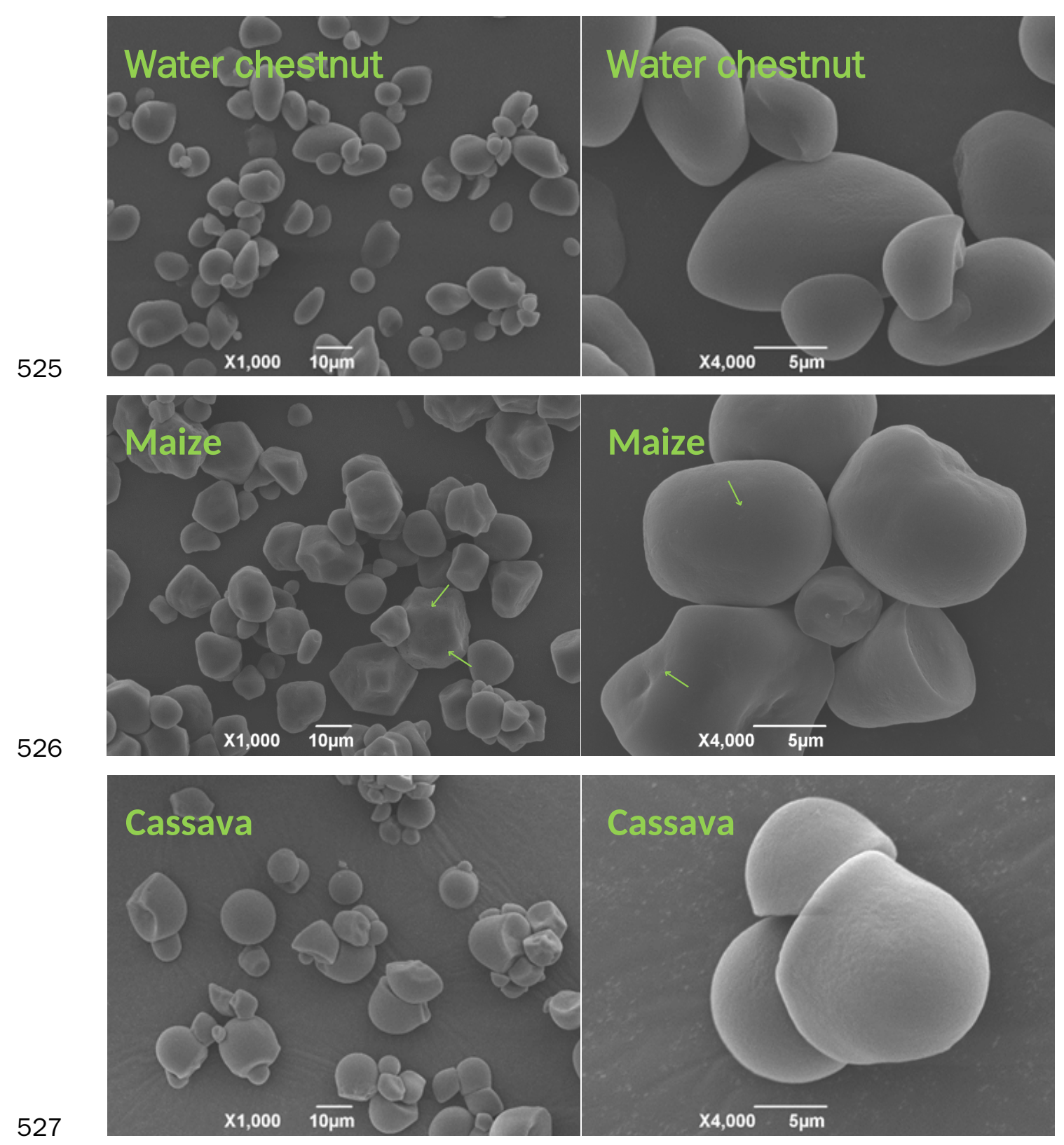

528

529 Fig. 1 


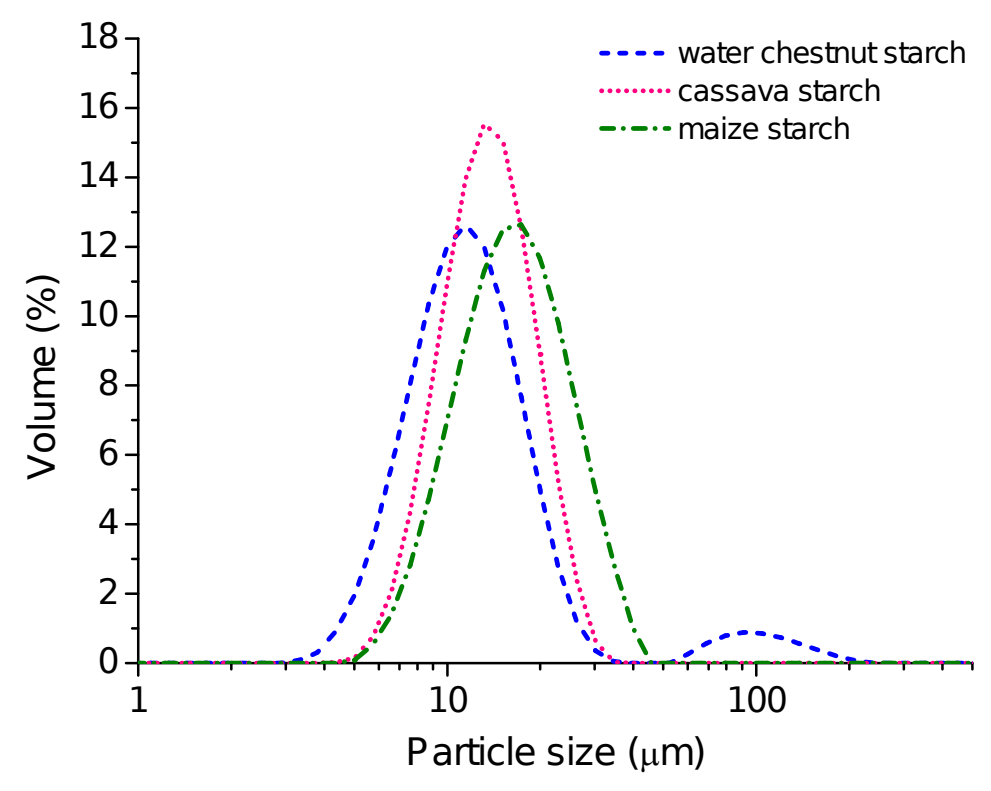

531 Fig. 2 


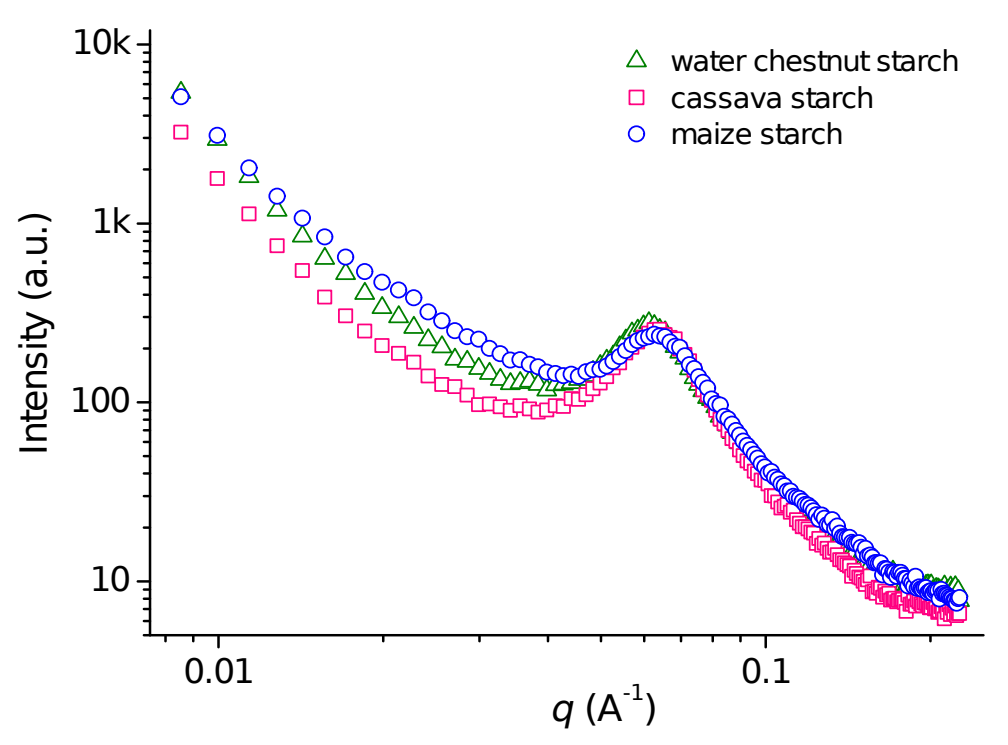

$533 \quad$ Fig. 3 


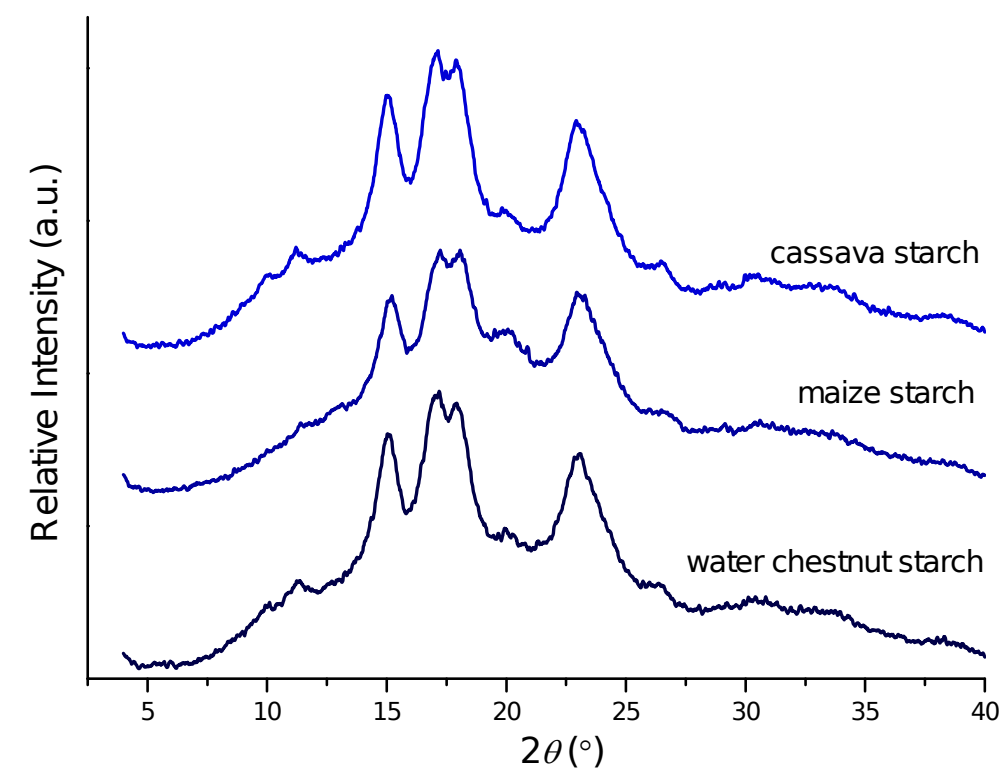

535 Fig. 4 

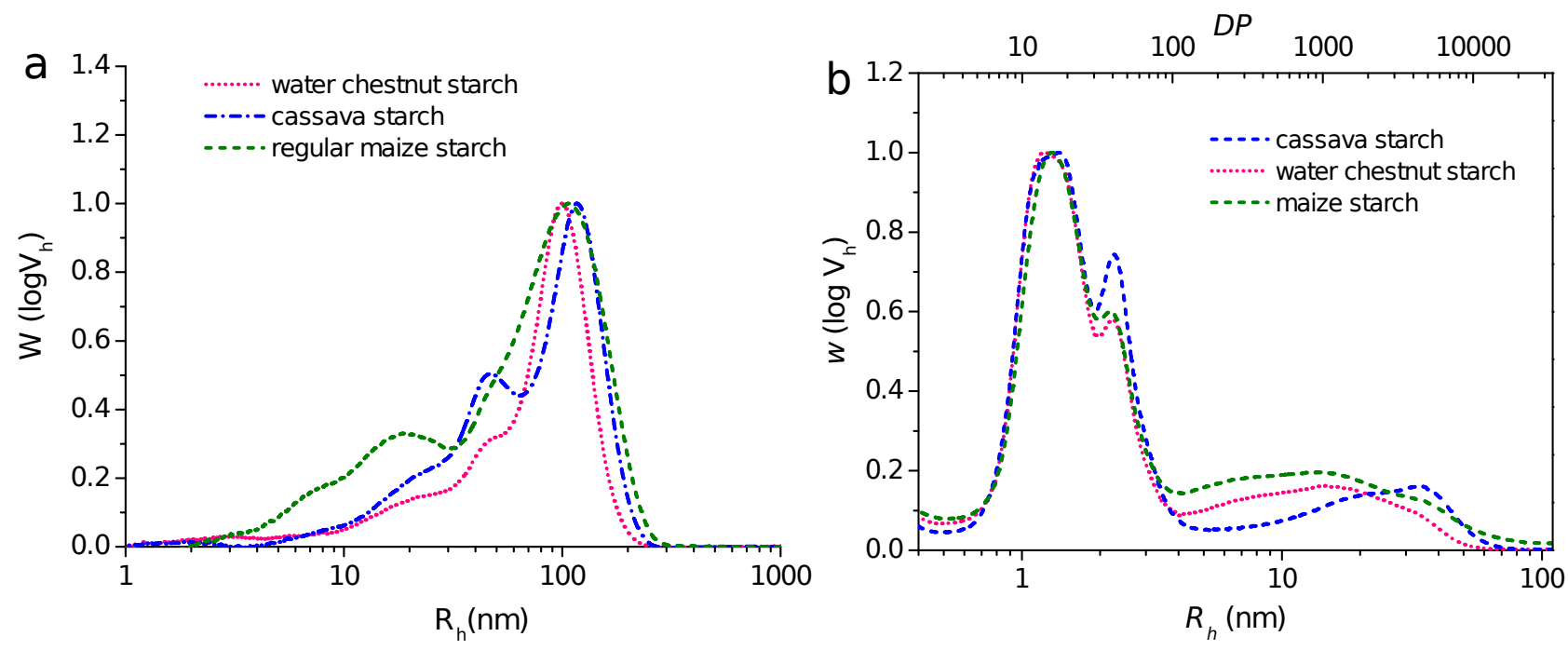

536
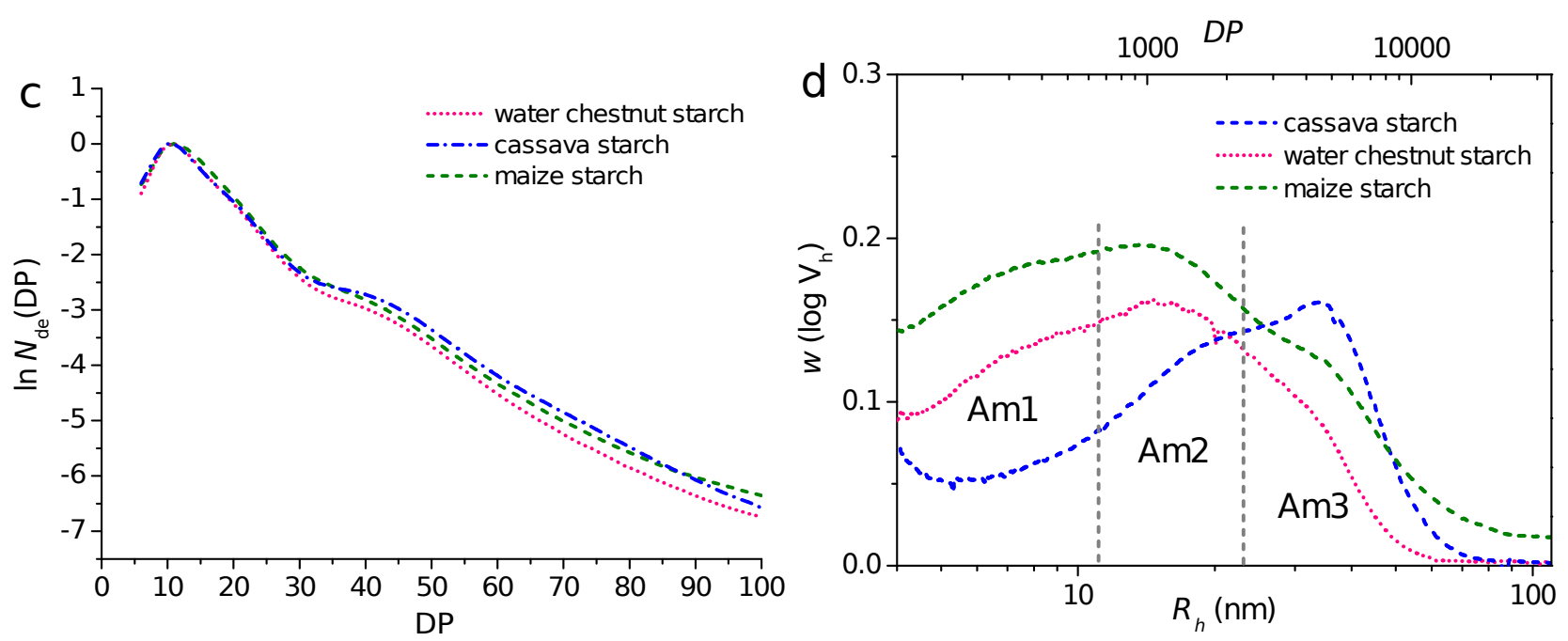

Fig. 5 

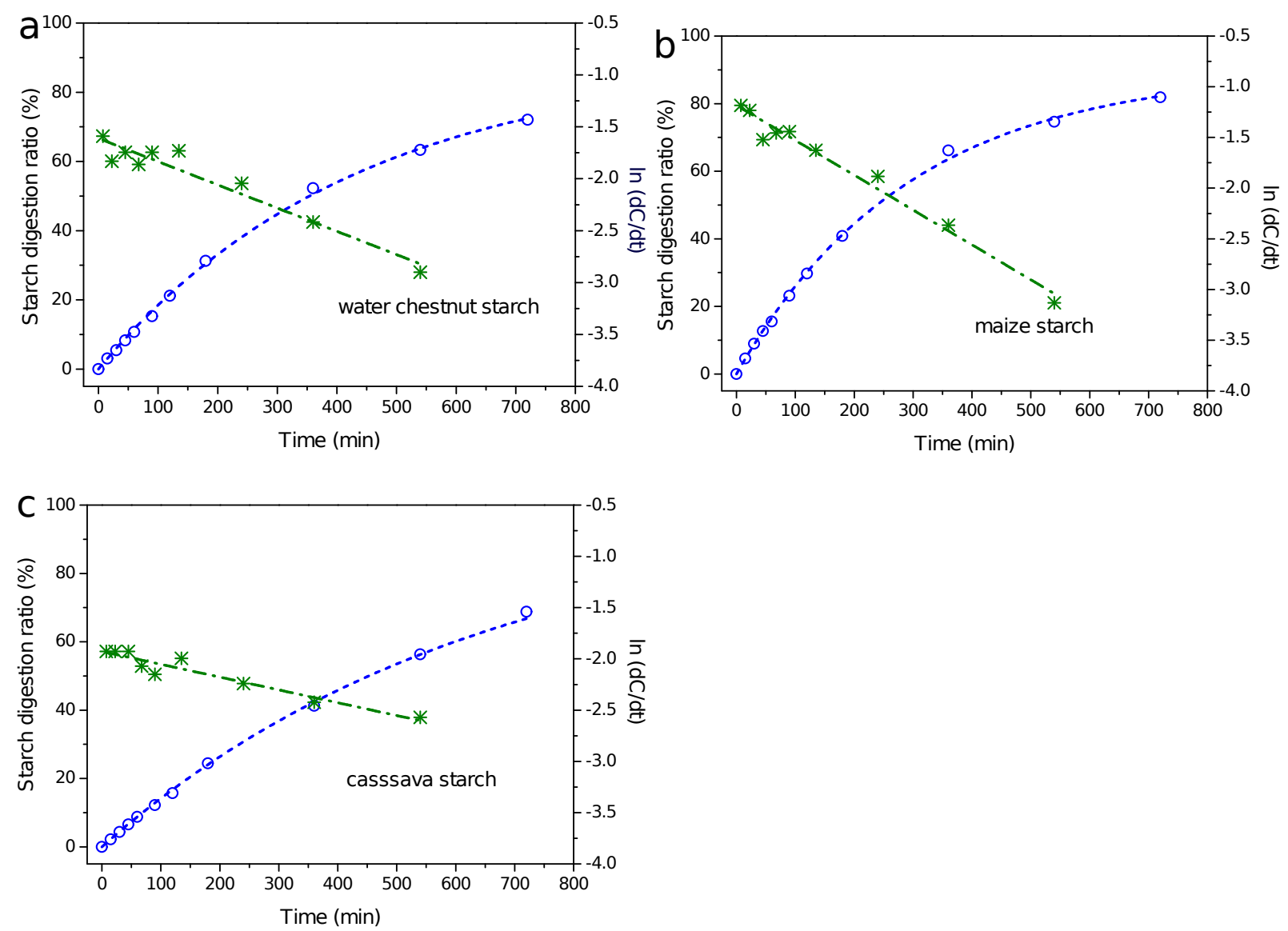

541

542 Fig. 6 

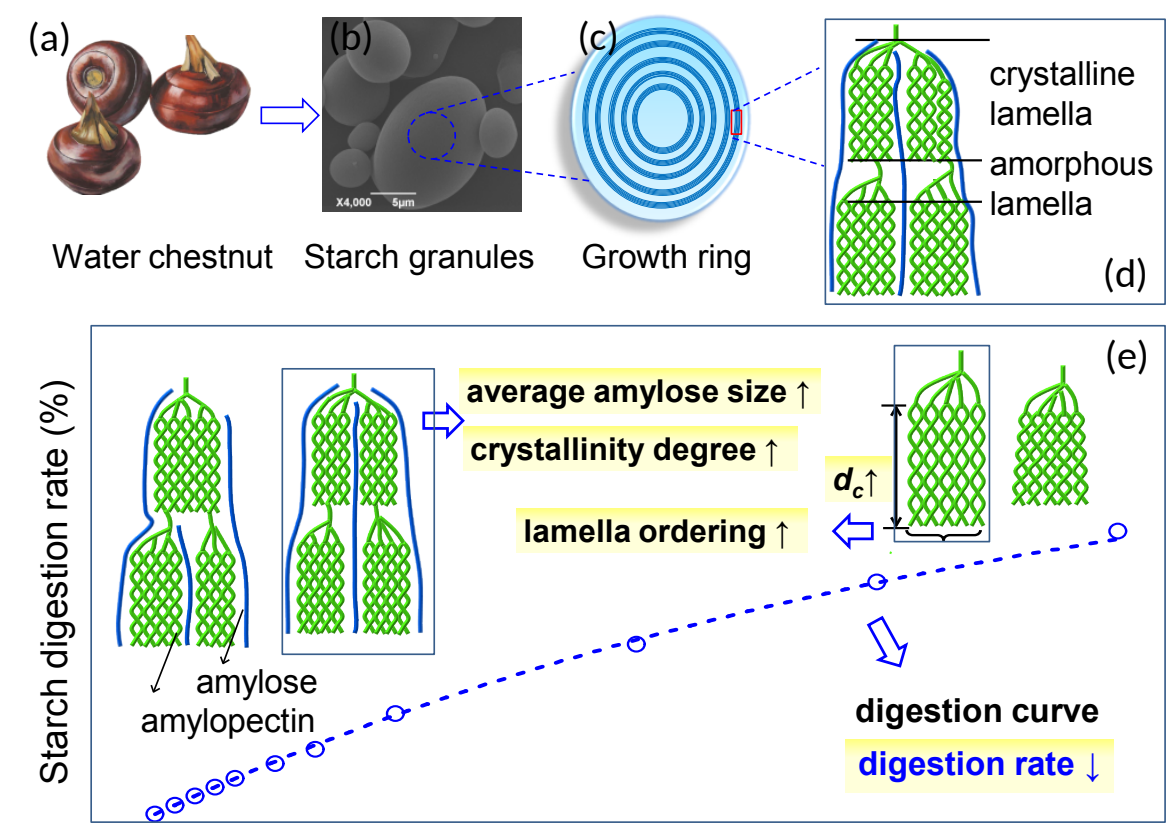

Time (min)

\section{$544 \quad$ Fig. 7}


545 Table 1 Granule size distributions of water chestnut, maize and cassava starches ${ }^{A}$

\begin{tabular}{llll}
\hline & water chestnut starch & maize starch & cassava starch \\
\hline $\mathrm{D}[4,3]$ & $15.77 \pm 0.14^{b B}$ & $18.82 \pm 0.07^{a}$ & $15.19 \pm 0.02^{c}$ \\
$\mathrm{D}[3,2]$ & $10.09 \pm 0.01^{c}$ & $15.98 \pm 0.06^{a}$ & $13.57 \pm 0.02^{b}$ \\
$d_{(0.1)}(\mu \mathrm{m})$ & $6.26 \pm 0^{c}$ & $10.12 \pm 0.03^{a}$ & $9.23 \pm 0.01^{b}$ \\
$d_{(0.5)}(\mu \mathrm{m})$ & $10.80 \pm 0^{c}$ & $17.49 \pm 0.07^{a}$ & $14.46 \pm 0.02^{b}$ \\
$d_{(0.9)}(\mu \mathrm{m})$ & $19.62 \pm 0.07^{c}$ & $29.54 \pm 0.13^{a}$ & $22.18 \pm 0.03^{b}$ \\
span & $1.237 \pm 0.007^{a}$ & $1.111 \pm 0.002^{b}$ & $0.896 \pm 0$ \\
size $0-50 \mu \mathrm{m}$ & $94.81 \pm 0.13^{b}$ & $100 \pm 0^{a}$ & $100 \pm 0^{a}$ \\
size $50-300 \mu \mathrm{m}$ & $5.19 \pm 0.13^{a}$ & $0^{b}$ & $0^{b}$ \\
\hline
\end{tabular}

$546{ }^{A} \mathrm{D}[4,3]$, mean diameter over the volume distribution; $\mathrm{D}[3,2]$, mean diameter over the surface

547 distribution; $d_{(0.1)}, 10 \%$ of the overall granules showed a size less than this value $(\mu \mathrm{m}) ; d_{(0.5)}, 50 \%$ of

548 the overall granules showed a size less than this value $(\mu \mathrm{m}) ; d_{(0.9)}, 90 \%$ of the overall granules

549 showed a size less than this value $(\mu \mathrm{m})$; span, a value equal to $\left(d_{(0.9)}-d_{(0.1)}\right) / d_{(0.5)}$.

$550{ }^{B}$ Values followed by the different lowercase letter in a row differ significantly $(P<0.05)$. 
551 Table 2 Lamellar and crystalline parameters of water chestnut, maize and cassava starches ${ }^{A}$

\begin{tabular}{llll}
\hline Sample & water chestnut starch & maize starch & cassava starch \\
\hline$d(\mathrm{~nm})$ & $9.29 \pm 0.02^{a B}$ & $9.17 \pm 0.03^{b}$ & $9.17 \pm 0.02^{b}$ \\
$d_{\mathrm{c}}(\mathrm{nm})$ & $6.70 \pm 0.02^{a}$ & $6.62 \pm 0.02^{b}$ & $6.52 \pm 0.01^{c}$ \\
$d_{\mathrm{a}}(\mathrm{nm})$ & $2.59 \pm 0^{b}$ & $2.55 \pm 0.01^{c}$ & $2.65 \pm 0.01^{a}$ \\
$A_{\text {peak }}($ a.u. $)$ & $4.10 \pm 0.02^{a}$ & $3.05 \pm 0.11^{c}$ & $4.04 \pm 0.02^{b}$ \\
$X_{\mathrm{c}}(\%)$ & $48.15 \pm 0.79^{a}$ & $44.69 \pm 0.25^{c}$ & $45.55 \pm 0.33^{b}$ \\
\hline
\end{tabular}

$552{ }^{A}$ Parameters measured by SAXS: $d$, average thickness of semicrystalline lamellae; $d_{\mathrm{c}}$, average

553 thickness of crystalline lamellae; $d_{\mathrm{a}}$, average thickness of amorphous lamellae; $A_{\text {peak }}$, the area of 554 scattering peak. Parameters measured by XRD: $X_{\mathrm{c}}$, relative degree of crystallinity.

$555{ }^{B}$ Values followed by the different lowercase letter in a row differ significantly $(P<0.05)$. 
556 Table 3 Molecular and digestion parameters of water chestnut, maize and cassava starches ${ }^{A}$

\begin{tabular}{|c|c|c|c|}
\hline Sample & water chestnut starch & maize starch & cassava starch \\
\hline $\bar{R}_{\mathrm{h}, \text { amylose }}(\mathrm{nm})$ & $29.52 \pm 0.08^{b B}$ & $12.71 \pm 1.78^{c}$ & $36.53 \pm 1.29^{a}$ \\
\hline$h_{\mathrm{Ap} 2 / \mathrm{Ap} 1}$ & $0.5735 \pm 0.0066^{b}$ & $0.6191 \pm 0.0091^{b}$ & $0.7432 \pm 0.0001^{a}$ \\
\hline$A_{\mathrm{Am} 1}$ & $0.0038 \pm 0.0002^{a}$ & $0.0045 \pm 0.0002^{a}$ & $0.0020 \pm 0.0002^{b}$ \\
\hline$A_{\mathrm{Am} 2}$ & $0.0133 \pm 0.0003^{b}$ & $0.0173 \pm 0.0003^{a}$ & $0.0139 \pm 0.0001^{b}$ \\
\hline$A_{\mathrm{Am} 3}$ & $0.0114 \pm 0.0009^{b}$ & $0.0255 \pm 0.0048^{a}$ & $0.0136 \pm 0.0006^{b}$ \\
\hline Amylose content $(\%)$ & $24.76 \pm 0.01^{a}$ & $25.90 \pm 1.30^{a}$ & $20.01 \pm 0.01^{b}$ \\
\hline$k_{\mathrm{LOS}}\left(\min ^{-1}\right)$ & $0.0020 \pm 0.0002^{b}$ & $0.0033 \pm 0.0001^{a}$ & $0.0013 \pm 0.0001^{c}$ \\
\hline$k_{\text {fitting }}\left(\min ^{-1}\right)$ & $0.0021 \pm 0.0002^{b}$ & $0.0033 \pm 0.0001^{a}$ & $0.0014 \pm 0.0001^{c}$ \\
\hline$C_{12}(\%)$ & $71.96 \pm 0.11^{b}$ & $82.11 \pm 0.22^{a}$ & $69.01 \pm 0.22^{c}$ \\
\hline$C_{\infty}(\%)$ & $93.79 \pm 4.54^{a, b}$ & $90.26 \pm 0.32^{b}$ & $100 \pm 0^{a}$ \\
\hline
\end{tabular}

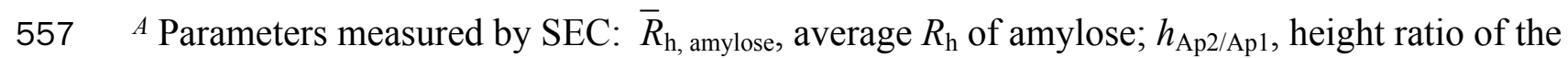
558 maximum of Ap2 peak to that of Ap1; $A_{\mathrm{Am} 1}, A_{\mathrm{Am} 2}, A_{\mathrm{Am} 3}$, the amounts of shorter, intermediate and 559 longer amylose chains in starch, respectively; Parameters related to starch digestion behaviors: $k_{\mathrm{LOS}}$ $560\left(\mathrm{~min}^{-1}\right)$, starch digestion rate coefficient derived from LOS plot; $k_{\text {fitting }}\left(\mathrm{min}^{-1}\right)$, starch digestion rate 561 coefficient derived from non-linear curve fitting; $C_{12}$, amounts of starch digested by enzyme after 12 $562 \mathrm{~h} ; C_{\infty}$, estimated percentage of starch digested by enzyme.

$563{ }^{B}$ Values followed by the different lowercase letter in a row differ significantly $(P<0.05)$. 